\title{
Os Quadrinhos de Mawil: Relato de caso
}

\section{Mawil's Comics: Case Report}

\author{
Augusto Machado Paim*
}

Resumo: No segundo semestre de 2012, o quadrinista alemão Mawil morou um mês em Porto Alegre a convite do Goethe-Institut. Desse intercâmbio surgiu uma HQ curta sobre a cidade publicada no jornal Tagesspiegel, de Berlim, e reunida na coletânea The Singles Collection, livro recentemente lançado na Alemanha que reúne as melhores colunas do autor para o jornal. Essa HQ sobre Porto Alegre também foi traduzida e publicada na edição online do jornal Zero Hora, ainda em 2012. 0 presente artigo é um relato do tradutor sobre essa experiência, focando na grande diferença de públicos do original e da tradução e nas estratégias utilizadas para contornar o problema.

Palavras-chave: Mawil; tradução de quadrinhos; Projeto Osmose.

Abstract: In the second half of 2012, the German comic artist Mawil lived for a month in Porto Alegre as a guest of the Goethe-Institut. This exchange resulted in a short comic on the city published in the Berlin newspaper Tagesspiegel and gathered in The Singles Collection, a recently in Germany released anthology that brings together the best columns of the author for the newspaper. This comic on Porto Alegre was also translated and published, still in 2012, in the online edition of the Brazilian newspaper Zero Hora. This article is a report by the translator about that experience, focusing on the large difference between the public of the original and the translation, as well as on the strategies used to solve the problem.

Keywords: Mawil; comics translation; Osmose Project.

\footnotetext{
" Doutorando na Universidade Bauhaus em Weimar com bolsa CAPES/DAAD.
} 


\section{Introdução}

Em setembro de 2015, o quadrinista alemão Mawil lançou em Berlim seu mais novo livro: The Singles Collection (editora Reprodukt) é uma compilação das melhores HQs publicadas pelo autor desde 2006 no jornal Tagesspiegel. Em meio a histórias sobre uma bicicleta roubada, o penoso processo de buscar carvão no porão para aquecer a casa durante o inverno, viagens do autor ao estrangeiro para participar de festivais de quadrinhos, também está lá, na página 97, uma história em quadrinhos sobre Porto Alegre. Isso mesmo, Porto Alegre! Afinal, Mawil morou durante um mês na capital

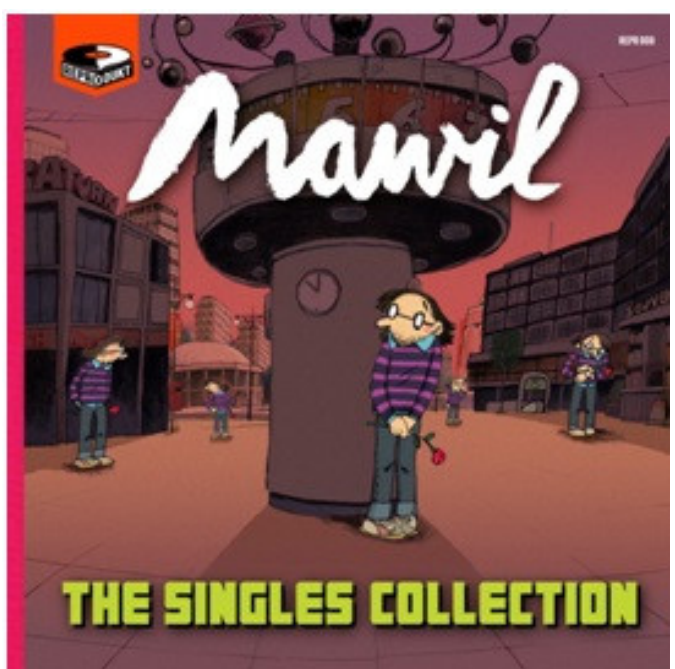

Figura 1: MAWIL 2015: capa. gaúcha a convite do Goethe-Institut.

Tive a oportunidade, na época, de traduzir essa HQ para o português. Tanto o original quanto a tradução são fruto de um acúmulo de experiências que se converteram em textos - verbal e icônico. E com especificidades que exemplificam os diferentes e complexos fatores que entram em jogo durante uma tradução. É sobre esse processo singular que quero falar aqui.

\section{0 autor}

Mawil é um autor renomado da cena de quadrinhos alemã, circulando tanto pelo meio underground quanto pelo mainstream. Nasceu em 1976, em Berlim, na então Alemanha Oriental. Tinha 13 anos quando o Muro caiu. Seu 
PaIM, A. M - Quadrinhos de Mawil: Relato de caso

trabalho de conclusão na Faculdade de Arte em Weissensee, em 2002, foi uma história em quadrinhos de 64 páginas: Wir können ja Freunde bleiben (publicado em 2012 no Brasil pela editora Zarabatana com o título Mas podemos continuar amigos...) é um relato autobiográfico, ora cômico, ora melancólico, sobre a timidez do autor e sua dificuldade em iniciar relacionamentos amorosos quando criança e adolescente.

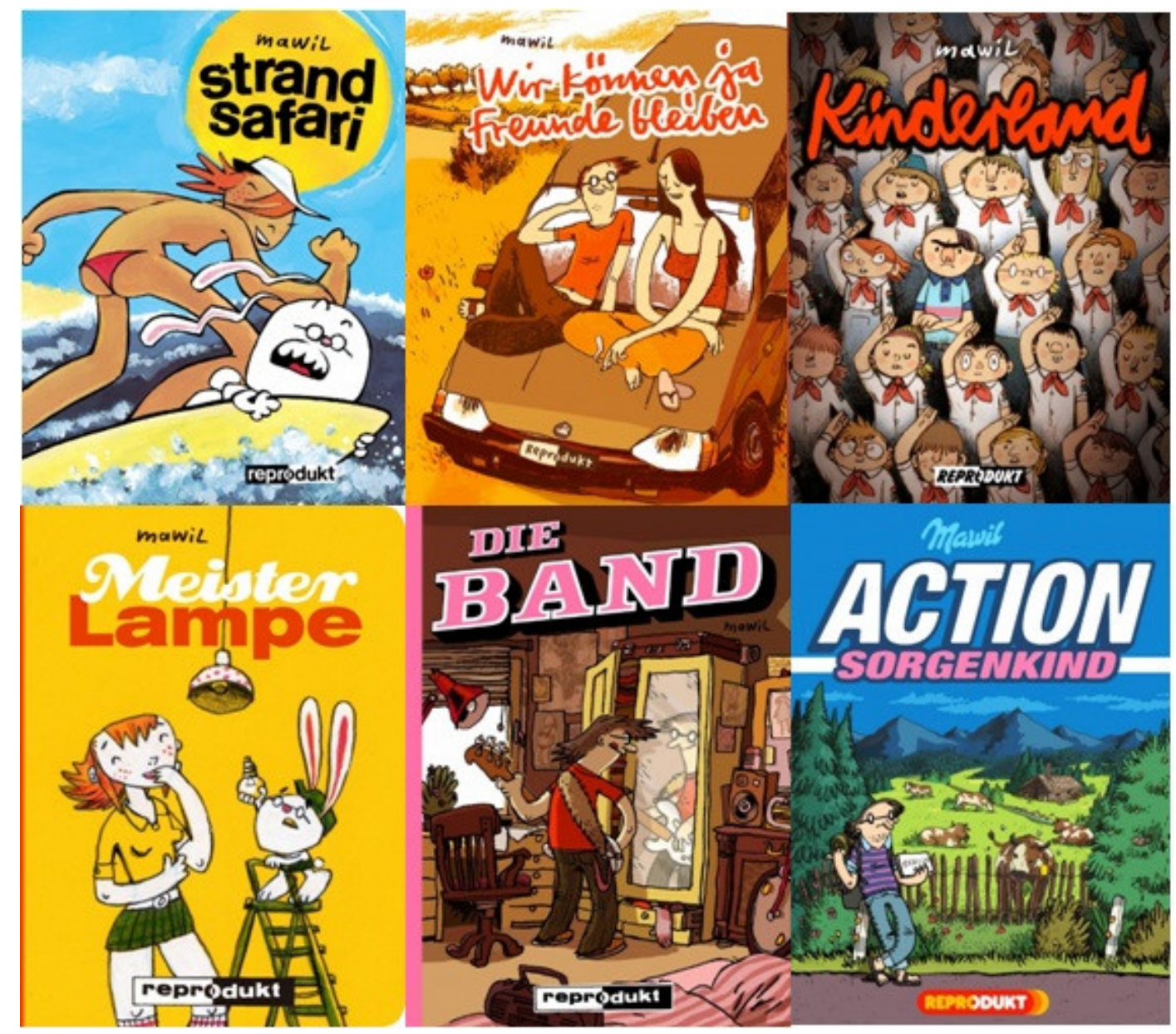

Figura 2: capas dos livros de Mawil publicados em alemão pela editora Reprodukt. Fonte: site do autor: http://www.mawil.net/.

Foi seu segundo livro - o primeiro chama-se Strand Safari. Além disso, ele já vinha publicando há tempos histórias curtas em fanzines e publicações independentes. Mas foi esse trabalho de conclusão que the deu a projeção que 
desfruta até hoje. Ali, Mawil já mostrava sua habilidade com o uso de layouts criativos, além de estabelecer desde então um estilo que torna fácil reconhecer os desenhos de sua autoria. Outra marca sua já presente aí é o domínio dos diálogos e da linguagem coloquial. Não é à toa que o livro continua sendo vendido e traduzido para outras línguas ainda hoje, mais de uma década depois (veja a seguir uma página dessa HQ).

Nas palavras de Matthias Shneider, jornalista alemão especializado em quadrinhos:

O quadrinista berlinense Markus Witzel, conhecido como Mawil, conseguiu algo que poucos conseguiram antes dele. Em um período de tempo curtíssimo e já com seus primeiros trabalhos, conquistou rapidamente os corações da comunidade de leitores de quadrinhos e convenceu completamente os críticos. Uma das razões para isso certamente está no modo charmoso e honesto em que relata suas experiências autobiográficas. (...) Suas histórias extremamente pessoais são encenadas com destreza e fluência em layouts de página magistrais, que ele habilmente organiza com trocas de perspectivas. $^{1}$

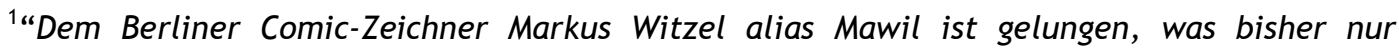
wenigen geglückt ist. Innerhalb kürzester Zeit und gleich mit seinen ersten Werken hat er in Windeseile die Herzen der comiclesenden Gemeinde erobert und die Kritiker auf ganzer Linie überzeugt. Einer der Gründe dafür liegt sicherlich in seiner charmanten und ehrlichen Art, mit der er seine autobiografischen Erlebnisse erzählt. (...) Seine extrem persönlichen Geschichten inszeniert er kunstfertig und flüssig in virtuosen Seitenlayouts, die er geschickt mit wechselnden Perspektiven arrangiert." (Texto de apresentação do artista para o site Deutschsprachige Comics do Goethe-Institut, disponivel em http://www.goethe.de/kue/lit/prj/com/cac/cam/de266570.htm)
} 
PaIM, A. M - Quadrinhos de Mawil: Relato de caso
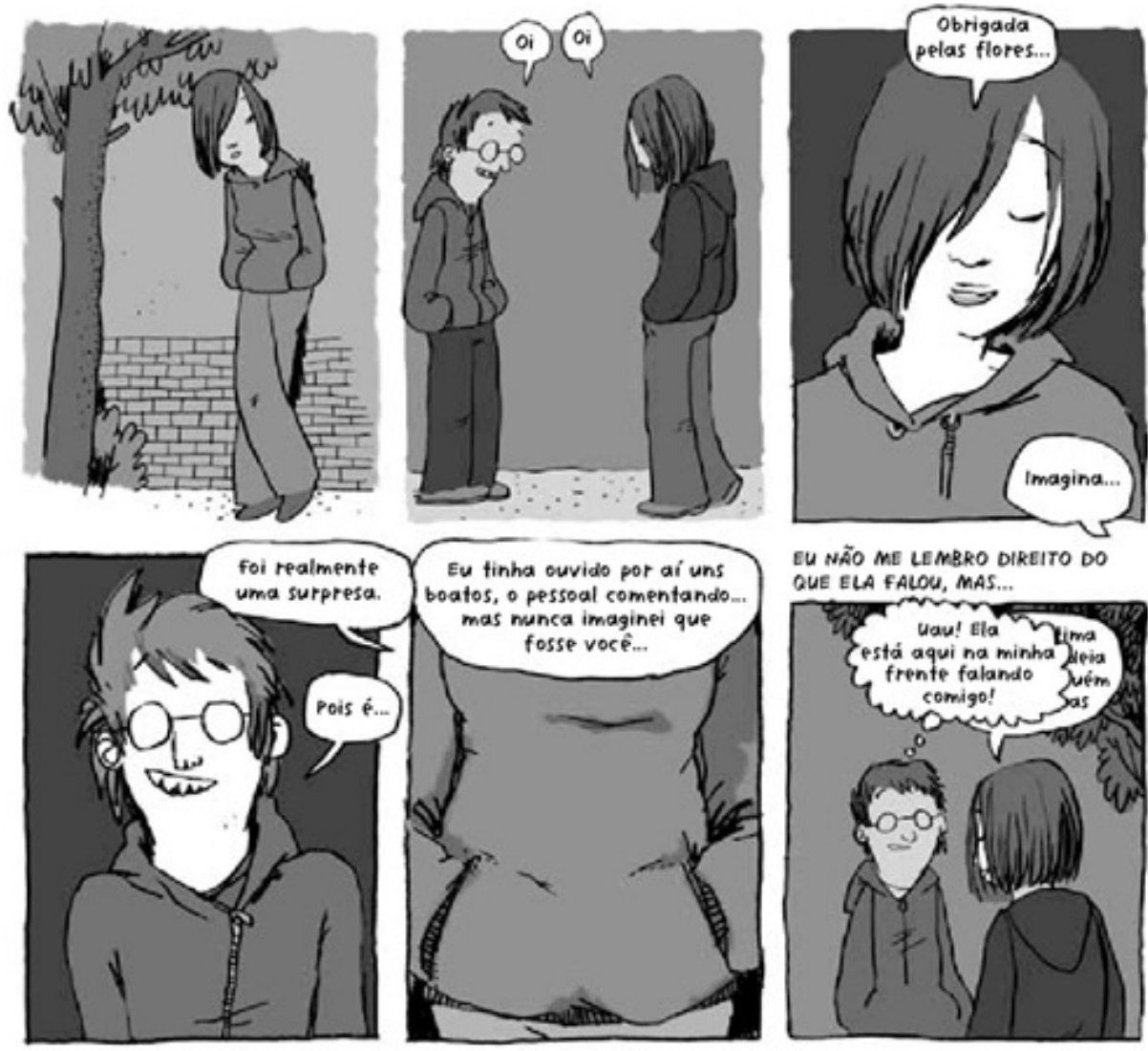

EU NĀO ME LEMBRO DIREITO DO QUE ELA FALOU, MAS...

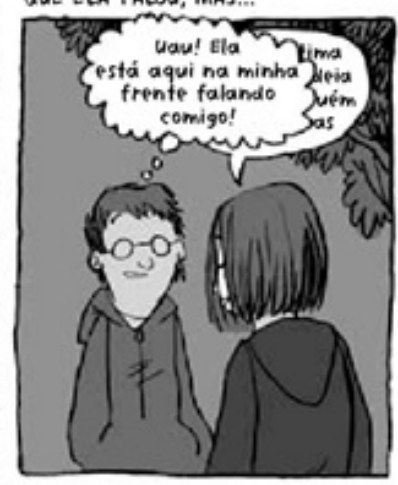

Hä... espero que você não me
leve a mal, mas...
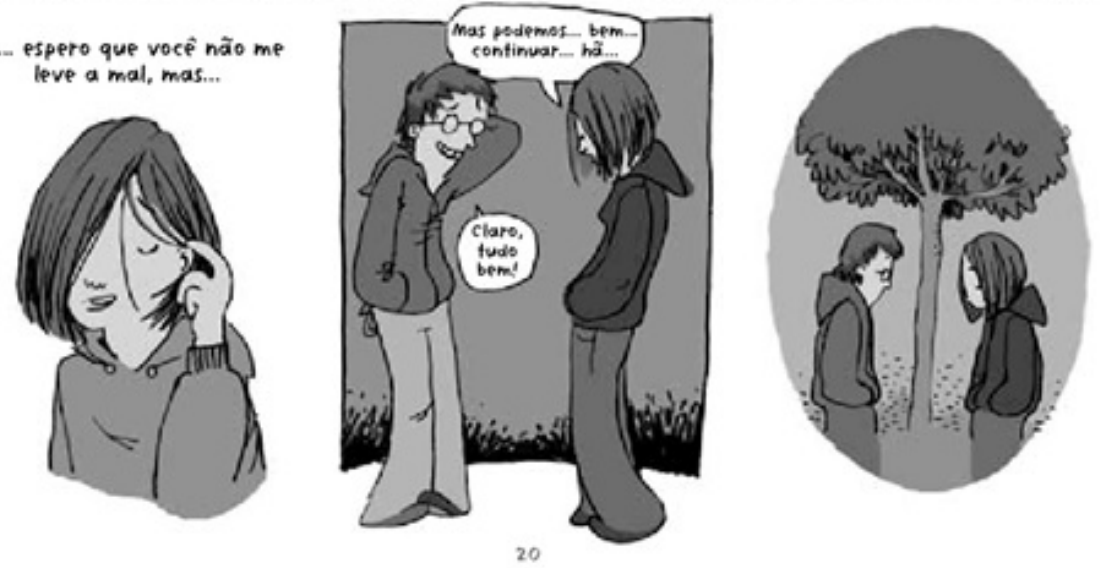

Figura 3: MAWIL 2012a: 20.

Seguiram-se outros livros curtos, como Die Band e Action Sorgenkind, além de Das grosse Super-Hasi-Album e Meister Lampe, sendo esses dois últimos histórias com a personagem-coelho que faz as vezes de superego do 
PAIM, A. M - Quadrinhos de Mawil: Relato de caso

autor. Apenas em 2014 Mawil publicou seu primeiro trabalho longo: Kinderland, uma graphic novel de quase 300 páginas narrando a vida de um menino de 13 anos da Alemanha Oriental que organiza um torneio de pinguepongue dias antes da queda do Muro. Por esse trabalho, Mawil venceu o Max \& Moritz 2014 do Salão de Quadrinhos de Erlangen, a maior premiação de quadrinhos da Alemanha.

\section{A viagem}

Em 2012, o Goethe-Institut Porto Alegre organizou um projeto de residências artísticas para quadrinistas chamado Osmose. Três autores brasileiros passaram um mês em três diferentes cidades alemãs; em contrapartida, três alemães estiveram no

Brasil. João Montanaro morou em Munique; Paula Mastroberti, em Berlim; Amaral, em Hamburgo; Aisha Franz, em Salvador; Birgit Weyhe, em São Paulo; e Mawil, portanto, foi para Porto Alegre. Durante o intercâmbio, os autores produziram desenhos, fotos e textos documentando essa experiência. Esse material foi disponibilizado no blog do Osmose ${ }^{2}$. Encerrado o intercâmbio, cada autor ainda produziu uma história de dez páginas baseada nessa experiência. As

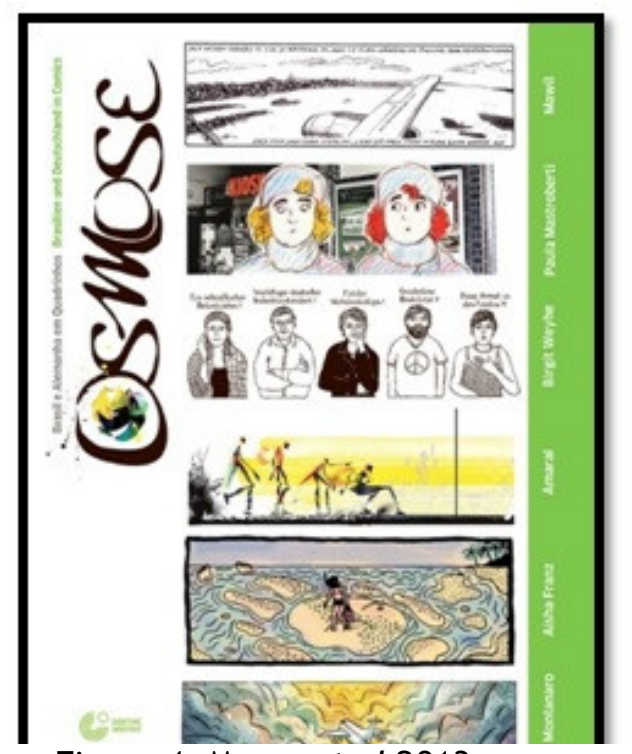

Figura 4: MAWIL et al 2013: capa. seis histórias foram reunidas em 2013 em

\footnotetext{
2 O blog do Osmose permaneceu no ar após o fim dos intercâmbios e o lançamento da antologia, mas foi desativado em 2016.
} 
PaIM, A. M - Quadrinhos de Mawil: Relato de caso

um livro publicado pela editora Libretos e lançado na Feira do Livro de Frankfurt.

Mawil morou um mês na capital gaúcha, entre o início de outubro e o início de novembro de 2012, mas também foi a Curitiba participar do festival de quadrinhos Gibicon, onde lançou seu livro pela editora Zarabatana. Esteve ainda em Florianópolis a convite dos quadrinistas Pedro Franz e Diego Gerlach. Pude acompanhá-lo a maior parte do tempo, pois eu estava morando em Porto Alegre na época, também participei da Gibicon daquele ano e ainda por cima era o curador do Osmose $^{3}$ e tinha a responsabilidade de atualizar o blog. Procurei organizar encontros e viagens que contribuíssem para o objetivo de proporcionar a Mawil uma experiência rica no Brasil - menos turística e mais próxima do quotidiano de quem mora na região. Fomos a uma festa de aniversário em Novo Hamburgo, a um churrasco de família na praia de Imbé, subimos a serra até Gramado e Canela para conhecer a colonização alemã no sul do Brasil. Mawil, por sua vez, esteve muito engajado em se aproximar da cultura de HQ local. Inclusive reuniu um grupo para realizar em Porto Alegre uma edição do "24 horas de quadrinhos", famoso evento internacional que acontece no mesmo dia em diferentes cidades.

Durante toda a viagem, Mawil esteve munido de um pequeno caderninho onde registrava suas experiências. Não raro, ele abria o caderninho durante uma confraternização e desenhava as suas impressões ali mesmo, com material de aquarela bem simples, desses que se compra para crianças em supermercados. Mawil também costumava colar nesse caderninho panfletos, adesivos e outros materiais que ia encontrando e despertavam sua atenção. Explico isso pois esse detalhe é importante para a técnica utilizada na HQ sobre Porto Alegre: alguns quadros dessa história são inspirados nos desenhos desse caderninho, e pode-se ver no primeiro quadro duas colagens.

\footnotetext{
${ }^{3} \mathrm{O}$ projeto Osmose teve idealização e coordenação de Reinhard Sauer, na época diretor do Goethe-Institut Porto Alegre, e coordenação editorial de José Aguiar.
}

TradTerm, São Paulo, v. 27, Setembro/2016, pp. 279-295

www.usp.br/tradterm

http://www.revistas.usp.br/tradterm/index 
PAIM, A. M - Quadrinhos de Mawil: Relato de caso
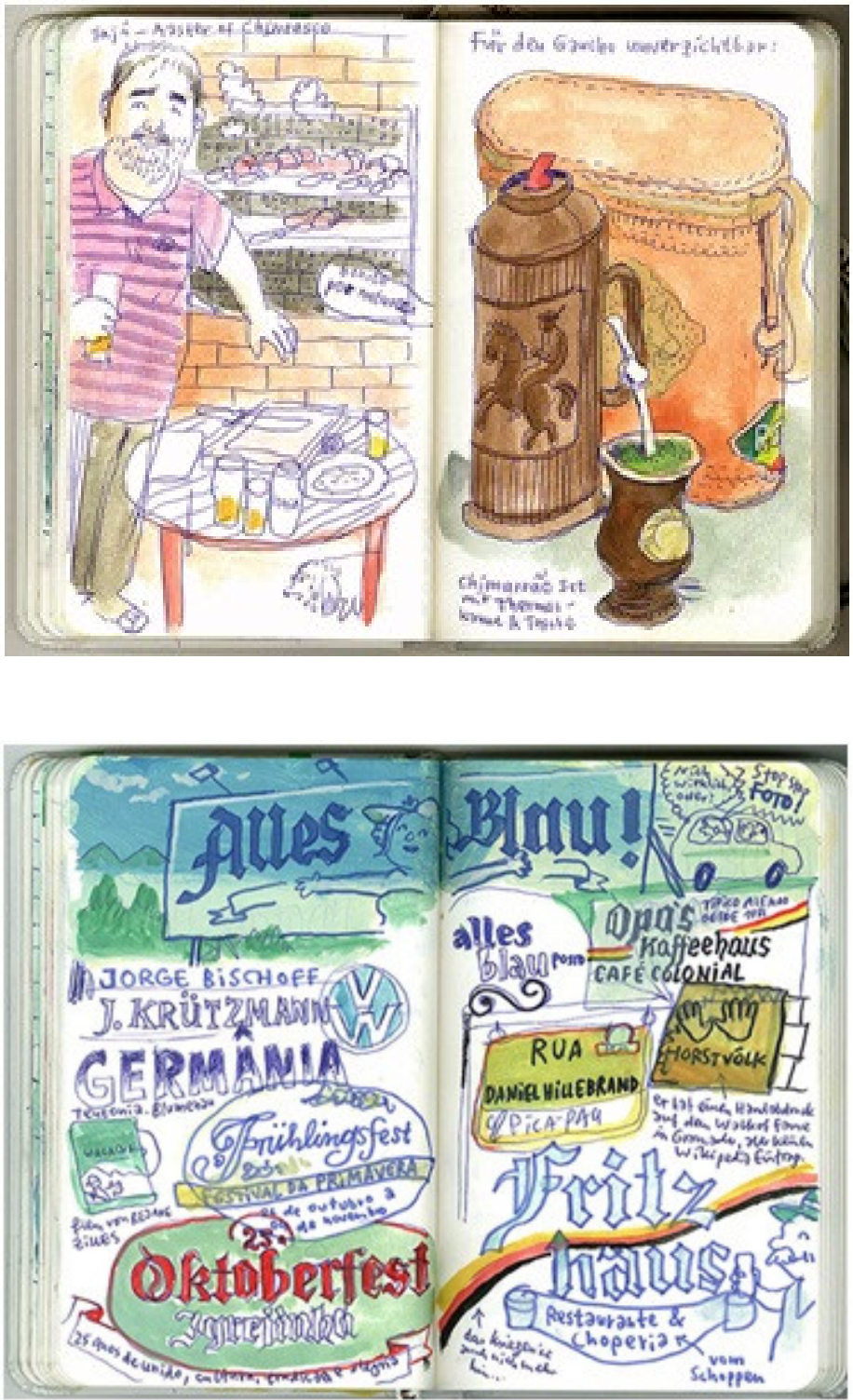

TradTerm, São Paulo, v. 27, Setembro/2016, pp. 279-295

www.usp.br/tradterm

http://www.revistas.usp.br/tradterm/index 
PaIM, A. M - Quadrinhos de Mawil: Relato de caso
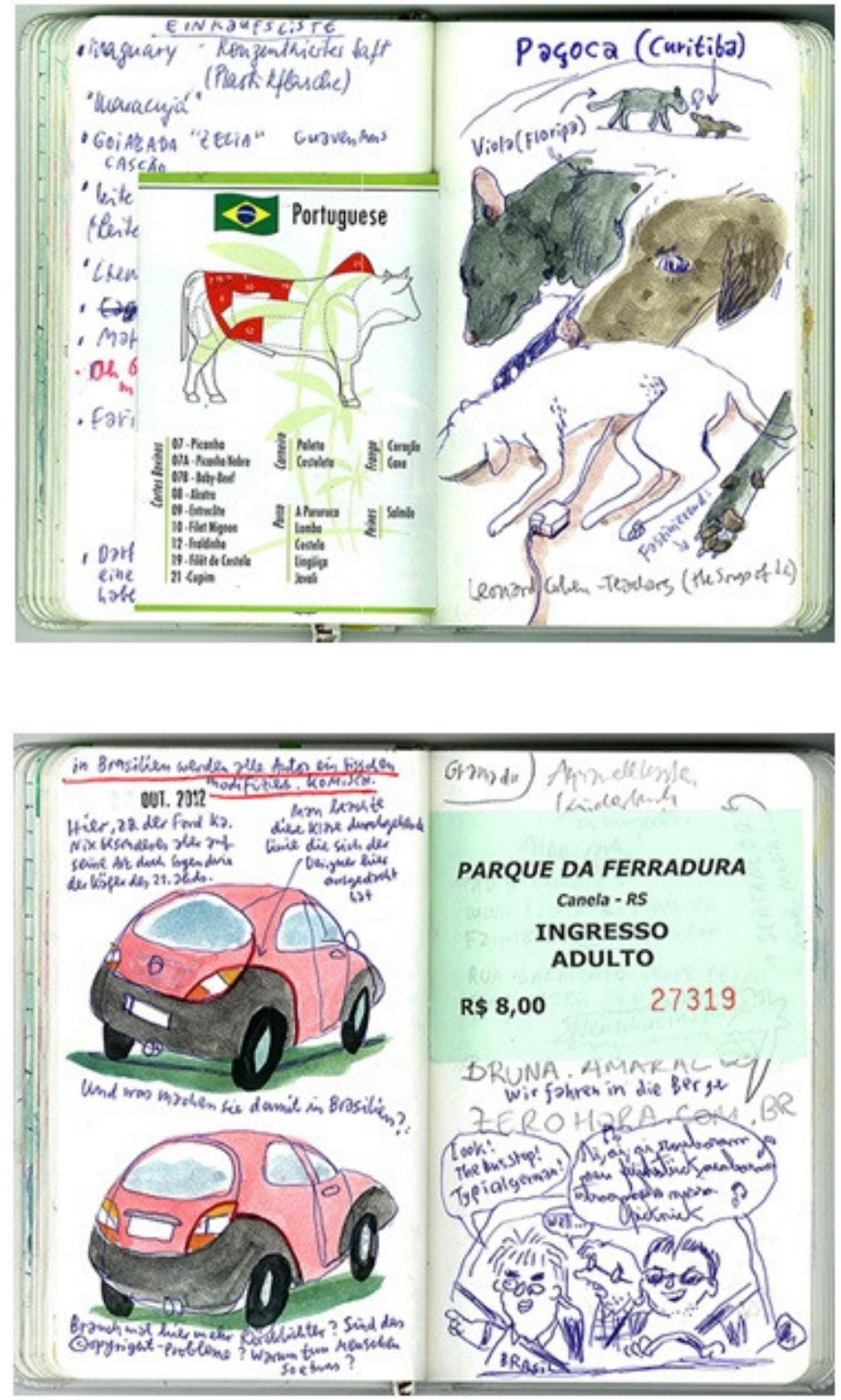

Figuras 5, 6, 7 e 8: excertos do caderno de esboços de Mawil, originalmente publicados no blog do projeto Osmose, não mais disponível. Fonte: arquivo pessoal do autor do artigo. 


\section{A história em quadrinhos}

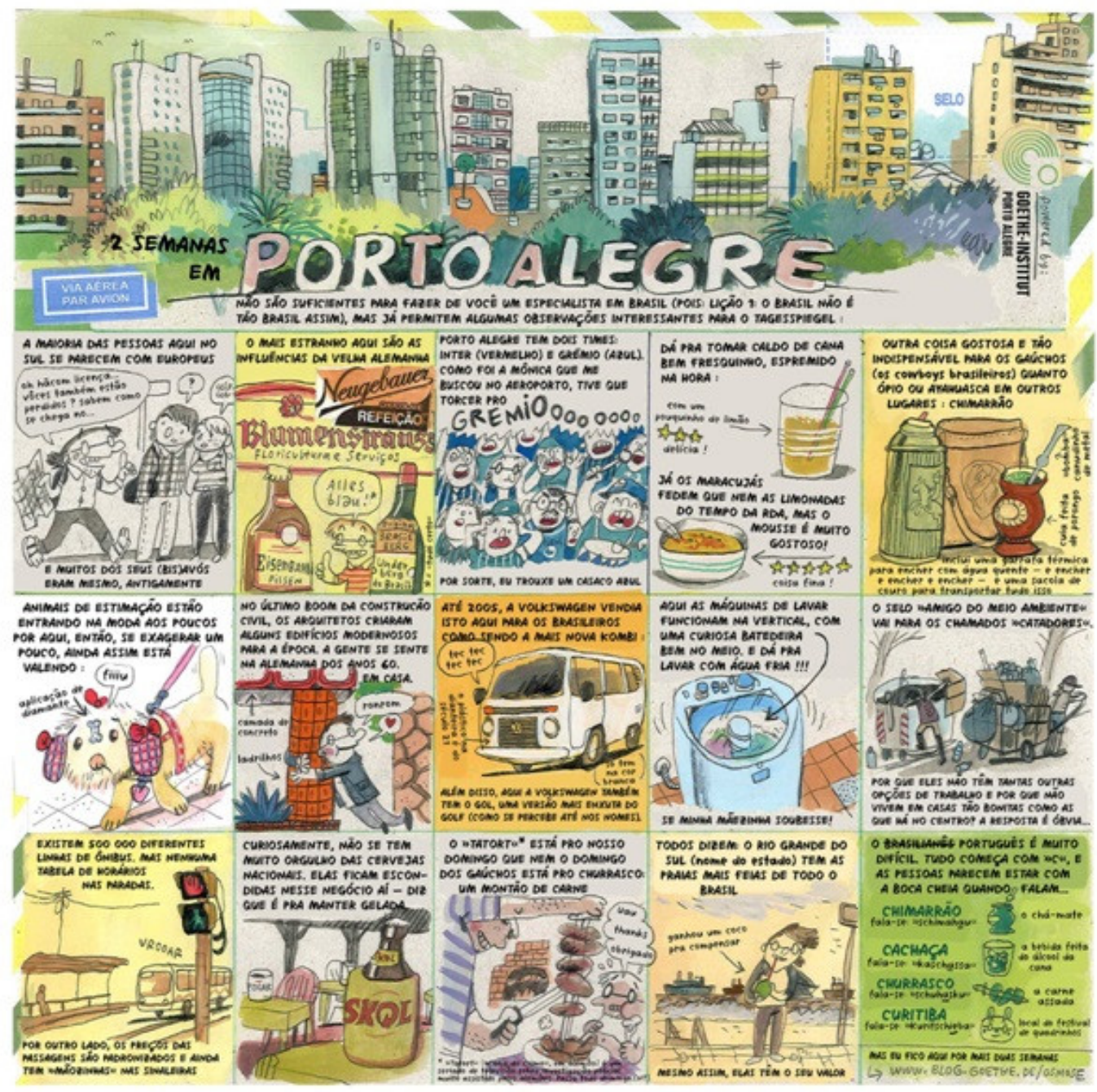

Figura 9: MAWIL 2012b, história em quadrinhos 2 semanas em Porto Alegre, publicada no jornal Zero Hora online em 30/10/2012. Disponível em alta resolução em: http://zerohora.rbsdirect.com.br/imagesrc/14173359.jpg

Uma vez por mês, desde 2006, Mawil faz uma HQ para o jornal Tagesspiegel. A periodicidade é seguida à risca. Por esse motivo, quando está viajando, ele costuma escrever e desenhar sobre suas viagens. Assim foi em Porto Alegre. Mesmo estando há apenas duas semanas na cidade, Mawil decidiu juntar as impressões esparsas que vinha recolhendo até ali em um 
PAIM, A. M - Quadrinhos de Mawil: Relato de caso

breve relato sobre sua experiência. Escolheu um formato mais tradicional, com 16 quadros de contornos regulares e, com exceção do primeiro, aproximadamente de mesmo tamanho. Essa opção destoa bastante das outras HQs presentes em The Singles Collection, em que há maior variação na maneira de organizar a página. Aliás, durante um dos eventos de lançamento do livro em Berlim, Mawil e Flix (outro autor que estava lançando uma coletânea com HQs publicadas no Tagesspiegel) enfatizaram que esse formato quadrangular proporciona muita liberdade criativa ao artista.

Uma questão fundamental dessa HQ é seu público-alvo. Mawil criou a história pensando em leitores alemães, principalmente berlinenses. Não estava nos planos iniciais traduzi-la. A ideia surgiu apenas durante uma visita que fizemos à redação do jornal Zero Hora. Dias depois, publicamos a versão em português no site do jornal. Ao longo das horas que se seguiram à publicação, a HQ foi compartilhada em redes sociais centenas de vezes por porto-alegrenses entusiasmados com o modo como um quadrinista alemão estava retratando a cultura gaúcha. Devo dizer que eu mesmo fiquei surpreso com a repercussão. Na minha timeline, comecei a ver pessoas de diferentes grupos de amigos - e amigos de amigos comentando essa $\mathrm{HQ}$, sem que soubessem que eu a havia traduzido.

Esse sucesso da
versão em português é
um fenômeno muito
particular, em se
tratando de um trabalho

com uma incomum diferença de público-

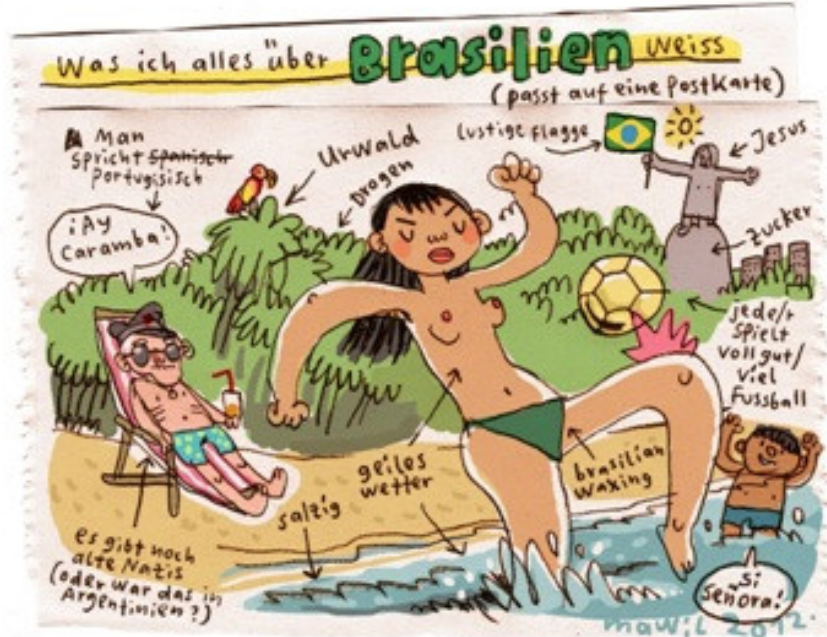

Figura 10: desenho de Mawil originalmente publicado no blog do projeto Osmose, não mais disponível.

Fonte: arquivo pessoal do autor do artigo. alvo. Mawil fez sua HQ para mostrar ao leitor berlinense, de forma humorística, os traços de cultura 
alemã que ainda estão muito presentes no sul do Brasil e o quanto essa cultura destoa de clichês que muitos europeus têm do nosso país. É um relato engraçado dos seus estranhamentos. No entanto, ao ser traduzida, a HQ encontrou um outro público: leitores porto-alegrenses de um jornal regional que percebiam, através do olhar estrangeiro, suas próprias peculiaridades e traços pitorescos. Trata-se de uma situação que não se vê com frequência em outras traduções: um original que versa sobre a cultura de chegada e se comunica com o público local da cultura de partida, e uma tradução que se comunica com o público local da cultura de chegada a partir de um olhar estrangeiro sobre essa mesma cultura. Para esse sucesso com ambos os públicos foi crucial o olhar aguçado de Mawil, que, mesmo não achando que seria lido por porto-alegrenses, fez uma HQ que não traz interpretações apressadas, preconceituosas ou cheias de clichês. Para ilustrar o que quero dizer com isso, trago o exemplo do desenho que pedimos que Mawil fizesse antes da viagem para Porto Alegre. Sem saber o que the esperava, ele decidiu ironizar os chavões sobre o Brasil que muitas vezes se ouve no exterior: que aqui se fala espanhol, o clima é ótimo, as drogas, o Cristo Redentor, o futebol etc. Nenhum desses elementos está presente na sua HQ para o Tagesspiegel, nem mesmo para fazer graça, como acontece no desenho mencionado (Figura 10). Pelo contrário, o autor repara em fatos do nosso quotidiano que com frequência passam despercebidos, como a ausência de uma tabela de horário nos pontos de ônibus e a negligência com a condição dos catadores de lixo.

\section{A tradução}

Acredito que uma parte do sucesso dessa $\mathrm{HQ}$ nas redes sociais também seja devida à tradução. Não me preocupei em traduzir literalmente a história em quadrinhos, evitei ser fiel ao original. Conhecendo o trabalho de Mawil há tanto tempo, eu queria que os leitores rissem durante a leitura da $\mathrm{HQ}$, assim 
PaIM, A. M - Quadrinhos de Mawil: Relato de caso

como costuma acontecer com os fãs berlinenses. Para construir esse efeito cômico que caracteriza seu estilo inconfundível, Mawil costuma fazer uso de uma linguagem muito coloquial, não raro usando o dialeto berlinense. Mas não é o que acontece nesse trabalho sobre Porto Alegre, em que o texto é informal, mas escrito em um alemão padrão. Mesmo sabendo disso, decidi adotar esta estratégia tradutória: usar uma linguagem bastante coloquial e, sempre que cabível, inserindo gírias locais (ajudou o fato de o público-alvo da tradução também ser regional, ou seja, a tradução não almejava ser lida por pessoas fora do Rio Grande do Sul). Meu objetivo maior foi traduzir o estilo do autor no modo como aparece na média de suas obras, mais do que apenas traduzir uma HQ em que esse estilo mal fica evidente para quem não está familiarizado com seu universo. Se o original foi publicado em um jornal berlinense e Mawil teve todo o cuidado de desenhar sobre Porto Alegre, sendo claro para esse público que desconhece a cidade, eu, ao traduzir sabendo que seria publicado na Zero Hora online, tive o cuidado redobrado de pensar no público porto-alegrense que desconheceria o contexto de Berlim. Uma fórmula intricada, mas que deu certo, como se percebe pelo número de compartilhamentos.

Fiz modificações pontuais no conteúdo de alguns quadros, tendo em vista esse problema. Por exemplo, no sétimo quadro da HQ original, Mawil comenta que as máquinas de lavar roupa no Brasil usam apenas água fria. Claro que não é verdade, e claro que ele sabia disso. Mawil usou minha máquina de lavar uma vez, um modelo bem simples. Expliquei para ele que há diferentes modelos. Mawil apenas quis fazer um comentário cômico direcionado ao leitor alemão, que não está acostumado a lavar roupa com água fria. Na versão em português, eu escrevi “e dá pra lavar com água fria”, pois, do contrário, tenho certeza que o leitor local entenderia como um erro, uma generalização precipitada do autor. Altera-se um pouco o conteúdo para que o efeito se mantenha.

Outro desafio foram as onomatopeias. Com frequência, elas já representam uma grande dificuldade da tradução de quadrinhos, mas em 
PaIM, A. M - Quadrinhos de Mawil: Relato de caso

muitos casos há um bom repertório de sons reproduzíveis em diferentes línguas que ajudam a contornar o problema. Não é o caso de Mawil, que costuma inventar suas próprias onomatopeias. Na tradução, tentei achar soluções que fossem compreensíveis no português da mesma forma que as suas criações são compreensíveis no alemão.

Somado a tudo isso, ainda havia o problema tradicional da tradução de HQ: o espaço reduzido. No original, quase não há espaços vazios entre os textos e os desenhos. Em vários momentos, o texto é até mesmo colocado na vertical ou na diagonal, fazendo-se o uso de setas. O fato de o próprio autor ter distribuído o texto da tradução acabou facilitando. Apesar de eu considerar essencial o trabalho de outros profissionais do ramo editorial como o acompanhamento da tradução e o letramento -, nesse caso específico a ausência de intermediários ajudou a dar agilidade ao processo. Eu enviava a tradução para Mawil, e ele ia colocando o texto na página, usando sua própria fonte. Nesse sentido, o processo de tradução se assemelhou ao processo de produção de uma $\mathrm{HQ}$ para um jornal, que envolve um ritmo e um procedimento diferente do ato de produzir uma história longa. A HQ de Mawil é, de fato, uma variação do que conhecemos como crônica.

O único problema tradutório que precisou de uma nota de rodapé para ser resolvido foi a menção ao programa Tatort, um seriado policial muito popular na Alemanha. Se eu tivesse alterado essa referência, trocando-o por qualquer outro equivalente brasileiro, causaria estranhamento ao leitor portoalegrense, que sabe que o autor vem de outra cultura. Já a pronúncia em alemão de palavras brasileiras no último quadro não precisou ser adaptada, pois o contexto fica claro para o leitor. 0 mesmo vale para as embalagens de produtos em alemão no terceiro quadro, que têm efeito cômico tanto para o público do original quanto da tradução em função da forte presença da colonização alemã no sul do Brasil. 
PAIM, A. M - Quadrinhos de Mawil: Relato de caso
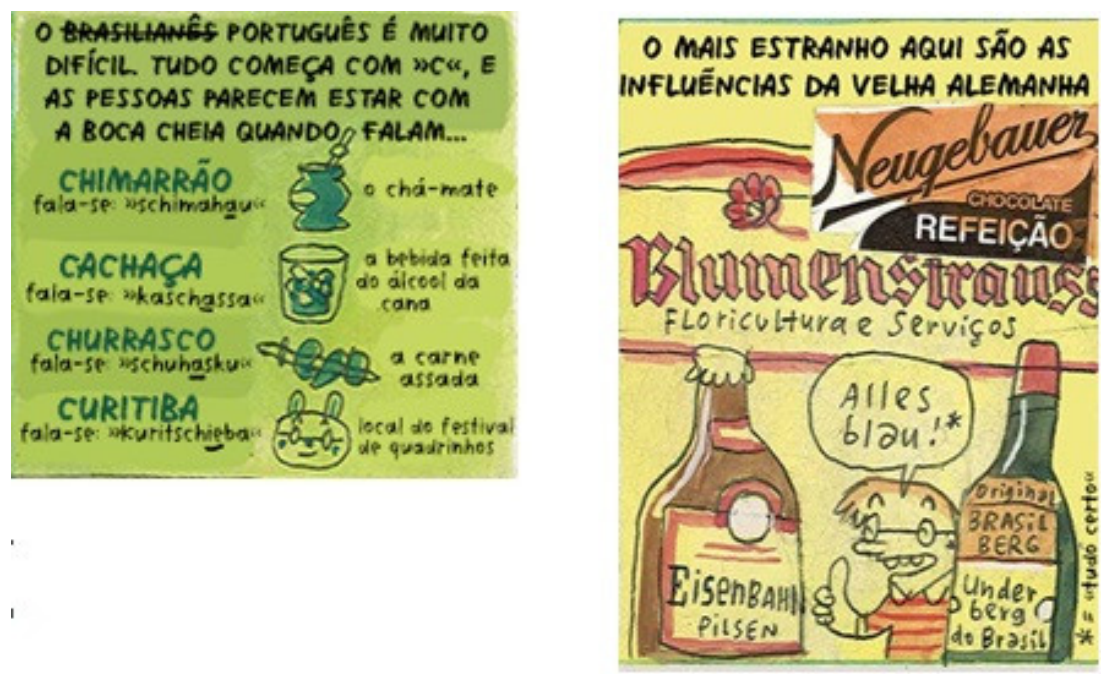

Figuras 11 e 12: MAWIL 2012b, quadros da história em quadrinhos 2 semanas em Porto Alegre, publicada no jornal Zero Hora online em 30/10/2012.

\section{0 tradutor}

Meu primeiro contato com a obra de Mawil aconteceu por acaso. Em 2007, eu estudava alemão no Goethe-Institut, em Porto Alegre, e decidi pegar algum livro emprestado na biblioteca do instituto para treinar o idioma. Eu já era jornalista formado e mantinha um blog onde escrevia sobre quadrinhos, mas não tive grandes pretensões na escolha do livro. Fui pela capa: a imagem de um casal triste na sacada de um apartamento. Pensei que se tratava de alguma história de separação. Não conhecia o autor. Só fui saber muito mais tarde que estava diante da capa antiga de Wir können ja Freunde bleiben.

A leitura me surpreendeu, o estilo do autor me cativou na hora. Fiquei tão entusiasmado que escrevi uma longa postagem no tal blog e enviei um email ao autor. Ele respondeu. Seguimos trocando algumas mensagens por algum tempo. Entre 2008 e 2009, estive na Alemanha por oito meses como au pair, ou seja, cuidando de crianças. Escrevi-lhe novamente e combinei uma visita ao seu ateliê. Esse foi nosso primeiro encontro presencial. Depois disso, 
PaIM, A. M - Quadrinhos de Mawil: Relato de caso

ao longo dos anos, foram surgindo novas oportunidades e essa relação foi se estreitando: traduzi seu livro e tive a honra de poder convidá-lo para viajar ao Brasil pelo Osmose, onde convivemos por praticamente um mês, de modo que, quando traduzi essa HQ para a versão online do jornal Zero Hora, eu já estava bastante imerso no universo do autor, e isso há pelo menos cinco anos. Foi essa sensação de conhecer muito bem tanto a obra quanto o artista que me deu a segurança de poder fazer uma tradução mais livre.

\section{0 cotradutor}

Concordo com quem diz que o tradutor tem o status de coautor da obra na língua de chegada. E concordo especialmente com o argumento de Érico Assis $^{4}$ de que, no caso dos quadrinhos, o letrista pode ser considerado um cotradutor, se entendemos a página de HQ como uma integração inquebrável de texto e imagem.

Defendo ainda que, nos quadrinhos, o próprio autor é cotradutor de sua obra em outra língua, pois uma grande parte dos efeitos de sentido de uma HQ estão expressos no desenho, que raramente precisam ser modificados na tradução. Esse peso do desenho na narrativa varia conforme o estilo do autor há alguns que enfocam o texto mais que o desenho. Especialmente no caso relatado aqui, em que o próprio autor fez o letramento, preservando assim as características do original de uma $\mathrm{HQ}$ em que o texto é muito integrado na

\footnotetext{
${ }^{4}$ Érico Assis é doutorando em Estudos da Tradução na Universidade Federal de Santa Catarina. Apesar de seu trabalho final de doutorado ainda estar em processo de escrita, tive a oportunidade de conhecer o argumento principal de sua tese durante a palestra que concedeu no congresso "Traduções e Adaptações de Quadrinhos", ocorrido na Universidade Hildesheim, na Alemanha, entre 31 de outubro e 2 de novembro de 2014. O argumento de Assis foi exposto nos anais do evento e também consta em seu artigo nesta edição de TradTerm.
} 
PaIM, A. M - Quadrinhos de Mawil: Relato de caso

sua forma de escrita ao desenho, podemos sem sombra de dúvida considerar Mawil cotradutor da versão em português.

\section{Referências bibliográficas}

MAWIL. Mas podemos continuar amigos... Campinas: Zarabatana, 2012a.

MAWIL. Duas semanas em Porto Alegre. Porto Alegre: jornal Zero Hora online, 2012b (publicado em 30/10/2012). Disponível em: http://zh.clicrbs.com.br/rs/entretenimento/noticia/2012/10/porto-alegre-etema-de-historia-em-quadrinhos-publicada-em-jornal-alemao-3934733.html MAWIL. The Singles Collection. Berlim: Reprodukt, 2015.

MAWIL; PAIM, A. et al. Osmose: Brasil e Alemanha em quadrinhos. Porto Alegre: Libretos, 2013. 